\section{Current Open Award Opportunities}

\section{Surgical Robotics Fellowship \\ Deadline April 15, 2016}

Familiarizes North American general thoracic fellows and their attending surgeons with the Da Vinci robotics system during two days of onsite, advanced training. Includes a $\$ 2,500$ grant to defray airfare to and accommodations at the training center.
Ethicon Fellowship for Advanced Minimally Invasive Thoracic Surgery

Deadline April 15, 2016

Offers North American young CT surgeons and their surgical teams the opportunity to enhance their skills in thoracic minimally invasive surgery by spending a one- or two-day period at clinical sites.

Apply for these awards online at aatsgrahamfoundation.org/ activities.cgi.

\section{The Western Thoracic Surgical Association}

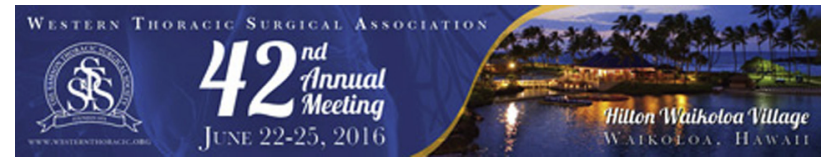

\section{WTSA 42nd Annual Meeting}

June 22-25, 2016

Hilton Waikoloa Village

Waikoloa, Hawaii

Visit the WTSA Web site at www.westernthoracic.org to:

- Register before the Monday, May 16, 2016, Early Bird deadline, and avoid a \$100 USD increase in most registration fees;

- Reserve your hotel room before the Wednesday, May 18,2016 , housing deadline (although it is possible the block of rooms - or specific room types—-set aside for the Western will fill before this cut-off date, so you are strongly encouraged to make your hotel reservations as soon as possible); and

- Receive updates on the latest Annual Meeting program details, venue activities, and local attractions.

\section{PRELIMINARY SCIENTIFIC HIGHLIGHTS}

Thursday, June 23, 2016

Presidential Address

John D. Mitchell, Aurora, CO

Controversies Debate

Concurrent Surgery: Efficient or Unethical?

Friday, June 24, 2016

Breakfast Session*

Public Reporting of Surgeon-Specific Data: Friend or Foe?

Postgraduate Course

War Surgery in Iraq and Afghanistan

Cameron D. Wright, Boston, MA
Saturday, June 25, 2016

C. Walton Lillehei Point/Counterpoint Session

Surgeons on the Heart Team: Quarterbacks or Water Boys?

\section{SOCIAL HIGHLIGHTS}

Each registration includes access to Wednesday's New Members/Welcome Reception, Thursday's Samson Fun Run and the Legends of Hawaii Luau-Our Big Island Story Theme Dinner, and Saturday's Family Luncheon and President's Banquet. (Registered children, ages 5-18, have access to supervised Children's Receptions during the New Members/Welcome Reception and President's Banquet.)

You may also supplement your Annual Meeting experience with these events:

- Thursday's Ocean Beach Blast*

- Friday's Golf Tournament*

- Friday's Tennis Tournament*

* Separate Registration Required

\section{ACCREDITATION}

This activity is being planned and implemented in accordance with the Essential Areas and Policies of the Accreditation Council for Continuing Medical Education (ACCME) through the joint providership of The American Association for Thoracic Surgery (AATS) and the Western Thoracic Surgical Association (WTSA). The AATS is accredited by the ACCME to provide continuing medical education for physicians.

This live activity will be designated for AMA PRA Category 1 Credit $(s)^{\mathrm{TM}}$. Physicians should claim only the credit commensurate with the extent of their participation in the activity.

\section{Applications for Membership}

The WTSA is now accepting Applications for Membership online for Active as well as Candidate membership status. Visit the WTSA Web site at www.westernthoracic.org to read the complete membership eligibility requirements and to initiate an online application. 